\title{
Oncological outcomes of lipofilling in breast reconstruction: a matched cohort study with 250 patients
}

\author{
Jose M. Casarrubios ${ }^{1,2}$, Mónica Francés ${ }^{1}$, Victor Fuertes ${ }^{3}$, Margit Singer $^{1}$, Carlos Navarro ${ }^{1}$, \\ Orlando García-Duque ${ }^{1}$, Javier Fernández-Palacios ${ }^{1}$
}

${ }^{1}$ Department of Plastic, Reconstructive \& Aesthetic Surgery, University Hospital Dr Negrín, Las Palmas de Gran Canaria, Spain; ${ }^{2}$ University of Las Palmas de Gran Canaria (ULPGC), Las Palmas de Gran Canaria, Spain; ${ }^{3}$ Department of Plastic, Reconstructive \& Aesthetic Surgery, University Hospital Miguel Servet, Zaragoza, Spain

Contributions: (I) Conception and design: JM Casarrubios; (II) Administrative support: J Fernández-Palacios, O García-Duque; (III) Provision of study materials or patients: J Fernández-Palacios, O García-Duque; (IV) Collection and assembly of data: JM Casarrubios, M Frances, V Fuertes, Margit Singer, C Navarro; (V) Data analysis and interpretation: JM Casarrubios, M Frances; (VI) Manuscript writing: All authors; (VII) Final approval of manuscript: All authors.

Correspondence to: Jose M. Casarrubios. Calle Plaza Barranco de la Ballena-Hospital Doctor Negrín, s/n. PC: 35010, Las Palmas de Gran Canaria, Spain. Email: casarrubiosbarrera@gmail.com.

Backgroundk Fat grafting is a procedure commonly used in breast reconstruction nowadays. Nevertheless, its oncological safety remains controversial. The potential risk that progenitor cells included in fat graft tissue may contribute to disease progression in patients with breast cancer is still debatable. We have designed a matchingcohort study with 250 patients with history of breast cancer trying to elucidate an answer for this question.

Methods: We selected 250 patients with a history of breast cancer in our hospital, between 2011 and 2019. A total of 125 patients (cases) had a history of breast cancer reconstructed with fat grafting. The additional 125 patients are matched controls. We analyzed the distribution of eight different variables within the cases and their matched controls: date of first oncological surgery, age, type of oncological surgery, histological subtype, Her-2 status, pN, smoking habit and diabetes mellitus. The objective of this study was to analyze the influence of fat grafting over breast cancer recurrence.

Results: There are not statistically significant differences in breast cancer locoregional recurrences $(\mathrm{P}=0.183)$, distant metastases $(\mathrm{P}=0.200)$ or total recurrences $(\mathrm{P}=0.065)$ amongst the two groups (cancer cases and matched controls).

Conclusions: Our study adds more information over the oncological safety of fat grafting. These findings should encourage long-term prospective trials to provide surgeons with accurate information regarding the role of lipofilling on breast neoplasms.

Keywords: Lipofilling; fat grafting; breast cancer; breast reconstruction; oncological safety

Submitted Oct 24, 2020. Accepted for publication Jan 04, 2021.

doi: $10.21037 / g s-20-775$

View this article at: http://dx.doi.org/10.21037/gs-20-775

\section{Introduction}

Fat grafting (sometimes also named lipofilling) is a procedure thoroughly used in breast reconstruction nowadays; either to improve the breast shape or to enhance skin quality by providing stem cells and growth factors. It helps surgeons to manage frequent complications in this reconstructive field, such as healing issues, breasts asymmetries and volume

^ ORCID: 0000-0001-5267-7388. 
deficits (1-4).

Its use is widely extended in both reconstructive and aesthetic surgery $(5,6)$ and even in pediatric patients (7).

The universal use of fat grafting in patients with a history of breast cancer implies the need of being certain that it is a safe procedure from the oncological point of view. This has certainly been a matter of debate in the past few years.

Some published studies performed in vitro and in animals show controversial results. In these papers, it is described that adipocytes and white adipose tissue progenitors produce growth factors that may be involved in the tumorigenesis process $(8,9)$. This has raised the concern of using this regenerating tissue in an oncological surgical field, making us wonder if this may increase the local tumor recurrence ratio $(10,11)$. Moreover, a review article published by Lohsiriwat et al., proposed that a "tumor-stroma interaction" can potentially induce cancer reappearance by "fueling" dormant breast cancer cells in the tumor bed (12).

Silva et al. recently published a study in an animal model describing fat grafting as an oncologically safe procedure (13). Many other articles have shown that fat grafting does not increase the local recurrence of breast cancer (14-17).

In 2009, the American Society of Plastic Surgeons set up a task forcing the Plastic Surgery community to assess the indications, safety and efficacy of fat grafting (18). They concluded that most of what was known came from expert's opinions and case series. Consequently, the knowledgeback then-was mostly based on low grade of scientific evidence. In 2015, the Haute Autorité de Santé Française established restrictions for the use of fat grafting (19).

All those different positions in the matter of fat grafting as a reconstruction technique in breast cancer have generate many controversies regarding the oncological safety of this technique.

Since this technique is currently being used in thousands of patients and has multiple indications, it is advisable to clarify its oncological safety. We have designed a matchingcohort study to analyze the influence of the use of lipofilling and the locoregional recurrence (LRR), distant metastases $(\mathrm{DM})$ and the total recurrences (TR) in patients with a prior history of breast cancer. Finally, we analyzed some additional patient's, tumor's and fat grafting's characteristics that could affect the prognosis.

We present the following article in accordance with the STROBE reporting checklist (available at http://dx.doi. org/10.21037/gs-20-775).

\section{Methods}

We selected patients from the Breast Cancer and Breast Reconstruction Database of our department and divided them in two groups. In the cases group, we have included patients with a history of breast cancer who were reconstructed with fat grafting (either as a single reconstructive procedure or in combination with another reconstructive procedure such as implant-based reconstructions or flaps) in our hospital, between 2011 and 2019. The exclusion criteria were patients with breast sarcomas, prophylactic mastectomies of BRCA positive patients, phyllodes tumors, positive margins after tumor excision and local recurrence before fat grafting. All of the patients included in the breast conserving surgery group received radiotherapy. The combination of breast conserving surgery and radiotherapy has showed to achieve similar surviving rates as compared to than mastectomy alone (20). All these 125 patients had undergone lipofilling according to the protocol of the Coleman technique $(21,22)$, with no additional cell enhancement.

The Controls were randomly selected among the patients with history of breast cancer who underwent any reconstructive procedure but fat grafting. They were matched with each case of the study with 8 variables: date of first oncological surgery (within 3 years), age (within 5 years), type of oncological surgery (breast conserving surgery and mastectomy), histological subtype, Her-2 status, pN, smoking habit and diabetes mellitus $(23,24)$ (Table 1$)$. Further cancer variables were compared between the 2 populations to ensure homogeneity.

Similar to Petit et al. (15), the selected control patient had a disease-free period at least as long as the time window between oncologic surgery and the fat grafting procedure of the corresponding study patient.

Clinical follow-up after tumor resection is performed every 3 months within the first year, every 6 months within the next 2 years and annually after that. Breast ultrasound and mammogram are performed annually in every patient weather Magnetic Resonance Imaging is requested only in selected patients.

Tumor recurrence was categorized as a local recurrence (LR) appearing in the same breast; and regional recurrence (RR) when in the axillar, infraclavicular and/or internal mammary lymph nodes. LRR is considered as the sum of LR and RR. DM is defined as the tumor presence anywhere else in the body-different from the breast and the areas described for the LRR.

The study was conducted in accordance with the 
Table 1 Clinical and demographic characteristics and follow up of the population

\begin{tabular}{|c|c|c|c|}
\hline & $\begin{array}{l}\text { Control } \\
(\mathrm{N}=125)\end{array}$ & $\begin{array}{l}\text { Lipofilling } \\
(\mathrm{N}=125)\end{array}$ & $P$ \\
\hline Age at cancer surgery, year & $47.2(24-67)$ & $45.6(29-71)$ & $0.118^{*}$ \\
\hline Year of cancer surgery & & & $0.783^{*}$ \\
\hline Before 2011 & $29(23.2 \%)$ & $33(26.4 \%)$ & \\
\hline 2011-2013 & 35 (28.0\%) & $39(31.2 \%)$ & \\
\hline 2014-2016 & $55(44.0 \%)$ & $47(37.6 \%)$ & \\
\hline 2017-2019 & $6(4.8 \%)$ & $6(4.8 \%)$ & \\
\hline Smoke & & & $0.670^{*}$ \\
\hline Yes & $31(24.8 \%)$ & $34(27.2 \%)$ & \\
\hline No & $73(58.4 \%)$ & $75(60.0 \%)$ & \\
\hline Former smoker & $21(16.8 \%)$ & $16(12.8 \%)$ & \\
\hline Diabetes mellitus & & & $0.634^{*}$ \\
\hline Yes & $11(8.8 \%)$ & $8(6.4 \%)$ & \\
\hline No & $114(91.2 \%)$ & $117(93.6 \%)$ & \\
\hline Type of surgery & & & $0.895^{\star}$ \\
\hline $\begin{array}{l}\text { Breast conservative } \\
\text { surgery }\end{array}$ & $43(34.4 \%)$ & $45(36.0 \%)$ & \\
\hline Mastectomy surgery & $82(65.6 \%)$ & $80(64.0 \%)$ & \\
\hline Histology & & & $0.247^{*}$ \\
\hline Invasive ductal & $100(80.0 \%)$ & $92(73.6 \%)$ & \\
\hline Invasive lobular & $15(12.0 \%)$ & $14(11.2 \%)$ & \\
\hline Ductal in situ & $10(8.0 \%)$ & $19(73.6 \%)$ & \\
\hline $\mathrm{pT}^{\dagger}$ & & & 0.123 \\
\hline is & $10(8.0 \%)$ & $19(15.2 \%)$ & \\
\hline 1 & $58(46.4 \%)$ & $42(33.6 \%)$ & \\
\hline 2 & $41(32.8 \%)$ & $46(36.8 \%)$ & \\
\hline 3 & $13(10.4 \%)$ & $17(13.6 \%)$ & \\
\hline 4 & $3(2.4 \%)$ & $1(0.8 \%)$ & \\
\hline $\mathrm{pN}^{\ddagger}$ & & & $0.672^{*}$ \\
\hline 0 & $56(44.8 \%)$ & $63(50.4 \%)$ & \\
\hline 1 & 57 (45.6\%) & $50(40.0 \%)$ & \\
\hline 2 & $7(5.6 \%)$ & $9(7.2 \%)$ & \\
\hline 3 & $5(4.0 \%)$ & $3(2.4 \%)$ & \\
\hline \multicolumn{4}{|l|}{ Receptors } \\
\hline Estrogen positive & $107(85.6 \%)$ & $112(89.6 \%)$ & 0.443 \\
\hline Progesterone positive & $92(73.6 \%)$ & $103(82.4 \%)$ & 0.126 \\
\hline Her-2 positive & $31(24.8 \%)$ & 27 (21.6\%) & $0.653^{*}$ \\
\hline
\end{tabular}

Table 1 (comtinued)
Table 1 (comtinued)

\begin{tabular}{|c|c|c|c|}
\hline & $\begin{array}{l}\text { Control } \\
(\mathrm{N}=125)\end{array}$ & $\begin{array}{l}\text { Lipofilling } \\
(\mathrm{N}=125)\end{array}$ & $\mathrm{P}$ \\
\hline Classification & & & 0.287 \\
\hline Luminal A & 69 (55.2\%) & $79(63.2 \%)$ & \\
\hline Luminal B & $16(12.8 \%)$ & $8(6.4 \%)$ & \\
\hline Triple negative & $9(7.2 \%)$ & $11(8.8 \%)$ & \\
\hline Subtype Her-2 positive & $31(24.8 \%)$ & $27(21.6 \%)$ & \\
\hline \multicolumn{4}{|l|}{ Other treatments } \\
\hline Lymphadenectomy & $63(50.4 \%)$ & $52(41.6 \%)$ & 0.204 \\
\hline Radiotherapy & $104(83.2 \%)$ & $109(87.2 \%)$ & 0.477 \\
\hline Chemotherapy & $100(80.0 \%)$ & $86(68.8 \%)$ & 0.059 \\
\hline Hormonal therapy & $110(88.0 \%)$ & 113 (90.4\%) & 0.684 \\
\hline \multicolumn{4}{|l|}{ Follow up, months } \\
\hline From cancer surgery & $85.0(25-251)$ & $95.3(38-266)$ & 0.079 \\
\hline $\begin{array}{l}\text { From cancer surgery to } \\
\text { LF }\end{array}$ & NA & $48.1(0-183)$ & \\
\hline $\begin{array}{l}\text { From the first LF } \\
\text { procedure }\end{array}$ & NA & $47.2(6-113)$ & \\
\hline
\end{tabular}

Data are expressed as absolute number (\%) or mean (range). *, matching variables; ${ }^{\dagger}$, pathological assessment of the primary tumor; ${ }^{\ddagger}$, pathological assessment of the regional lymph nodes.

Declaration of Helsinki (as revised in 2013). The study was approved by institutional ethics committee of University Hospital Dr Negrin (No. 2020-352-1) and individual consent for this retrospective analysis was waived.

\section{Statistical analysis}

The demographic and clinical data were compared between both groups, Cases and Controls, with the Fisher's exact test for the categorical variables, and the Student's $t$-test for the quantitative variables (Table 1).

LRR and DM are established as the primary end point. If there's no LRR nor DM, the observation period ends up with the last clinical follow up appointment.

LRR, DM and TR are compared with the Cox proportional hazards regression model in both groups. Different subgroups are also compared with the multivariate analysis and the analysis of the own characteristics of the lipofilling (Tables 2-4). Kaplan Meier and Long-Rank test were used to estimate the progression-free survival curves of LRR (Figure 1). Statistical significance was set up at $\mathrm{P}<0.05$ (two-tailed). Analyses were carried out with SPSS 25 (IBM SPSS Statistics for Mac, 
Table 2 Locoregional recurrence analysis for subgroups according to histology, biomolecular subtype and type of oncological surgery

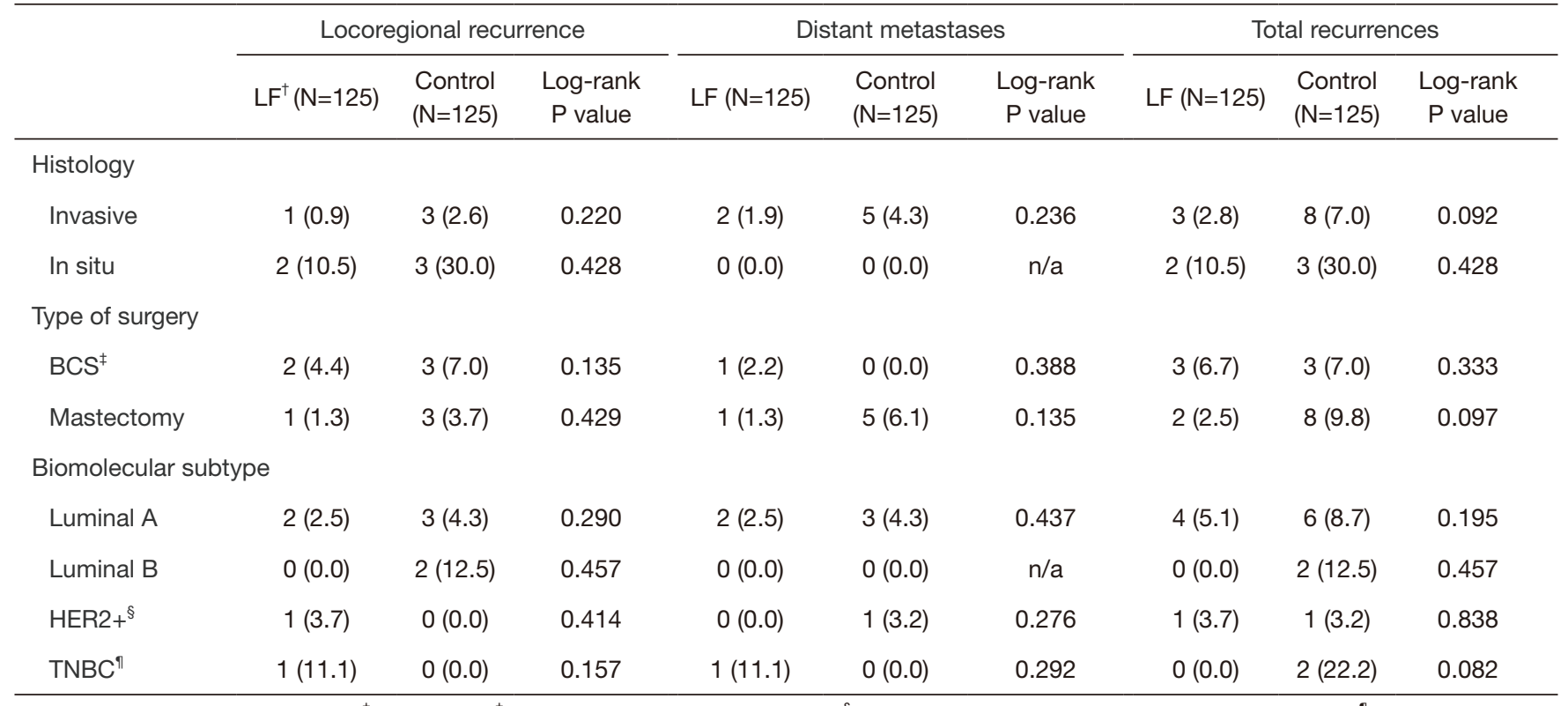

Data as expressed an $\mathrm{n}(\%) .{ }^{\dagger}$, lipofilling; ${ }^{\ddagger}$, breast conservative surgery; ${ }^{\S}$, human epidermal growth factor receptor $2 ;{ }^{~}$, triple negative breast cancer.

Table 3 Fat grafting variations depending on the oncological surgery type

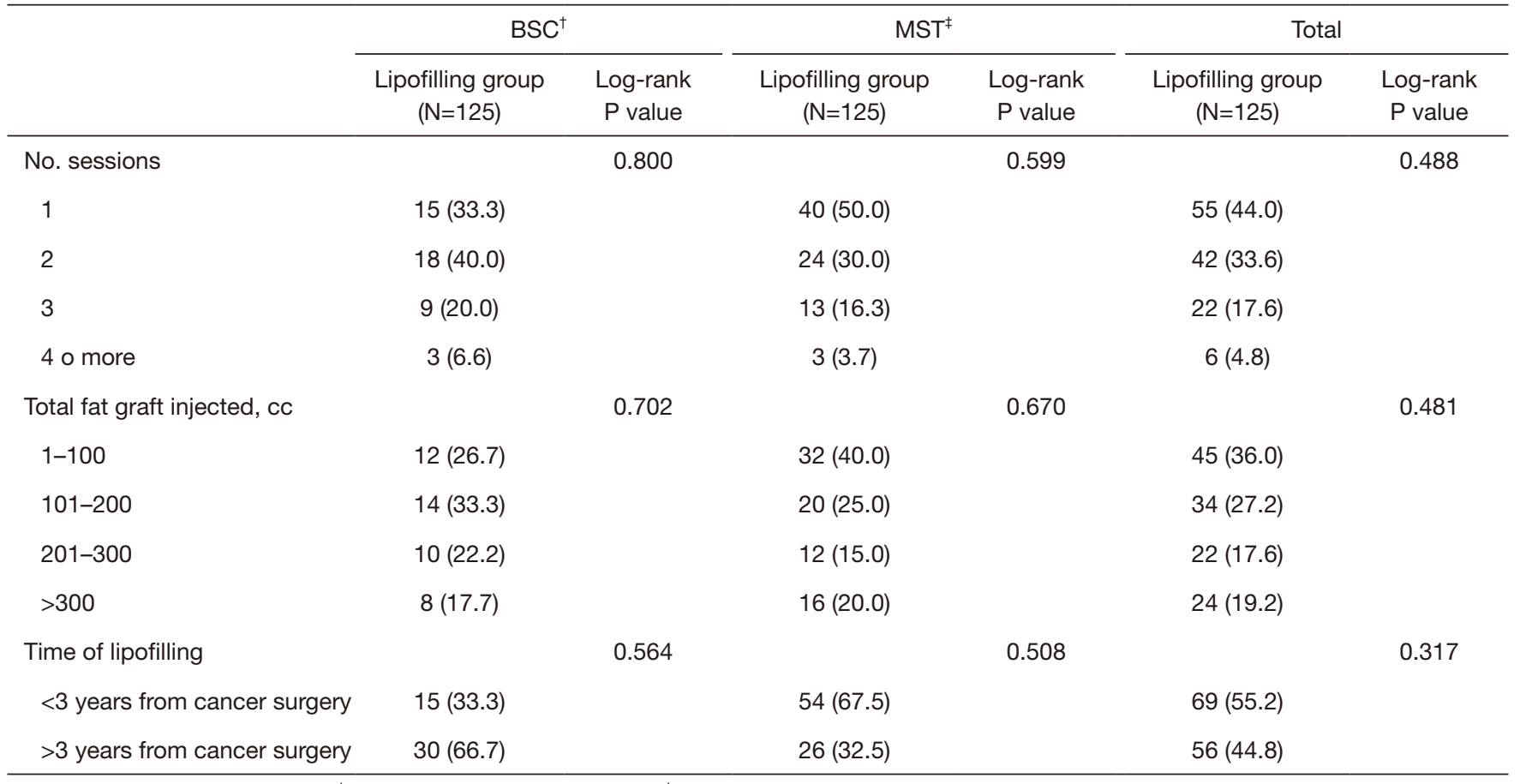

Data are expressed as $\mathrm{n}(\%) .{ }^{\dagger}$, breast conservative surgery; ${ }^{\ddagger}$, mastectomy. 
Table 4 Multivariate analysis of total recurrences

\begin{tabular}{|c|c|c|}
\hline & \multicolumn{2}{|c|}{ Total recurrences } \\
\hline & Hazard ratio $(95 \% \mathrm{Cl})$ & P-value \\
\hline Age at diagnosis & $1.01(0.95-1.08)$ & 0.266 \\
\hline \multicolumn{3}{|l|}{ Type of surgery } \\
\hline Lumpectomy vs. mastectomy & $1.34(0.42-4.29)$ & 0.622 \\
\hline \multicolumn{3}{|l|}{ Lipofilling } \\
\hline Performed vs. not performed & $0.30(0.09-1.01)$ & 0.051 \\
\hline \multicolumn{3}{|l|}{ pT stage } \\
\hline pTis vs. pT3-4 & $2.07(0.23-18.55)$ & 0.516 \\
\hline pT1-2 vs. pT3-4 & $0.17(0.04-0.71)$ & 0.014 \\
\hline \multicolumn{3}{|l|}{ pN stage } \\
\hline pNO vs. pN2-3 & $5.71(0.49-66.01)$ & 0.163 \\
\hline pN1 vs. pN2-3 & $3.79(0.36-39.47)$ & 0.266 \\
\hline \multicolumn{3}{|l|}{ Biomolecular subtype } \\
\hline Luminal $A$ vs. TNBC $^{\dagger}$ & $0.25(0.02-3.88)$ & 0.319 \\
\hline Luminal B vs. TNBC & $0.22(0.01-3.65)$ & 0.288 \\
\hline HER $2+{ }^{\ddagger}$ vs. TNBC & $0.23(0.02-3.60)$ & 0.295 \\
\hline \multicolumn{3}{|l|}{ Chemotherapy } \\
\hline Performed vs. not performed & $3.40(0.55-21.01)$ & 0.187 \\
\hline \multicolumn{3}{|l|}{ Hormone therapy } \\
\hline Performed vs. not performed & $2.53(0.19-33.91)$ & 0.483 \\
\hline \multicolumn{3}{|l|}{ Radiation therapy } \\
\hline Performed vs. not performed & $2.94(0.32-26.63)$ & 0.338 \\
\hline \multicolumn{3}{|l|}{ Lymphadenectomy } \\
\hline Performed vs. not performed & $1.18(0.25-5.47)$ & 0.836 \\
\hline \multicolumn{3}{|l|}{ Histology } \\
\hline $\mathrm{DCIS}^{\S}$ vs. IDC" & $0.56(0.01-3.14)$ & 0.507 \\
\hline $\begin{array}{l}\text { Invasive lobular carcinoma vs. } \\
\text { IDC }\end{array}$ & $0.56(0.01-3.14)$ & 0.507 \\
\hline
\end{tabular}

${ }^{\dagger}$, triple negative breast cancer; ${ }^{\ddagger}$, human epidermal growth factor receptor $2 ;{ }^{\S}$, ductal carcinoma in situ; ${ }^{\natural}$, invasive ductal carcinoma.

version 25.0; IBM Corp, Armonk, NY).

\section{Results}

A total of 249 fat grafting procedures for breast reconstruction were reviewed in 135 patients with history of breast cancer. A total of 10 patients were excluded from

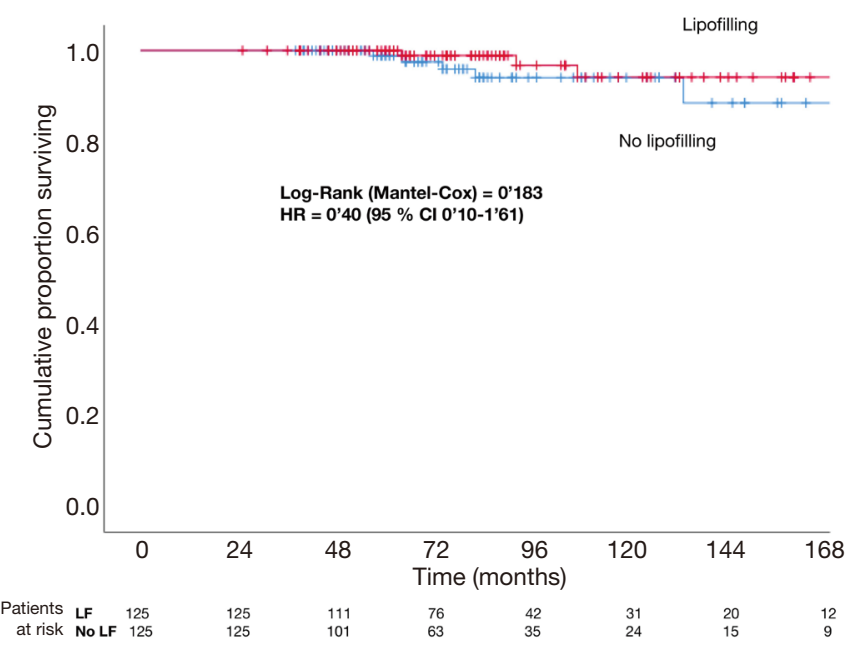

Figure 1 Locoregional progression-free survival for lipofilling and control group (Kaplan-Meier). HR, hazard ratio; CI, confidence interval; LF, lipofilling.

the study: 4 patients were excluded due to breast cancer recurrence before the lipofilling was performed; 4 patients were excluded because there were no controls to match the cases and 2 patients were excluded because oncological data was missing. Finally, a total of 232 lipofillings from 125 patients with history of breast cancer were included. Patients received an average of 1.86 lipofilling sessions with an average of $84.7 \mathrm{cc}$ (range, 20-280 cc) of fat grafting per session and an average of $157.2 \mathrm{cc}$ (range, 40-610 cc) of fat grafting per patient.

Fat grafting was used as the only reconstruction technique in 45 patients with breast conserving surgery defects. In 56 patients, it was used in combination with flaps and/or prostheses to improve breast shape. Finally, in 24 patients, lipofilling was used to improve skin quality prior to a heterologous reconstruction with implants in previously radiated patients to minimize the risk of implant extrusion (25). In 1 patient the lipofilling was performed at the time of the expansor insertion; whereas in the rest of the patients, lipofilling was performed prior the tissue expander insertion (6-183 months after oncologic surgery).

Characteristics of patients, tumors and surgery that may have influence in the prognosis were included in Table 1. 8 Matching variables were included. Those characteristics were analyzed between Cases and Controls. There were no statistically significant differences between both groups in any analyzed variables.

In the group of Cases there were 3 LRR (2.4\%) and 2 


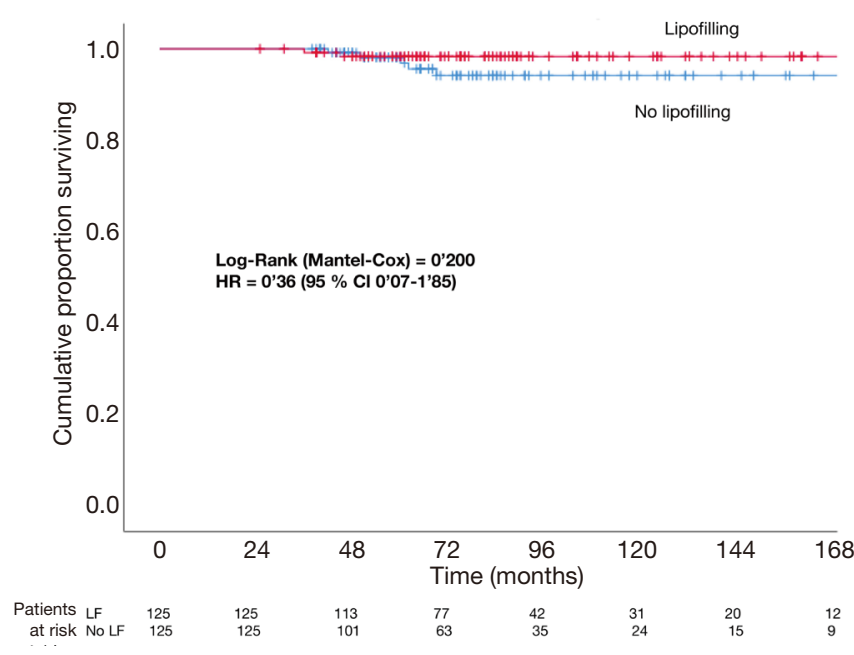

Figure 2 Distant progression-free survival for lipofilling and control group (Kaplan-Meier). HR, hazard ratio; CI, confidence interval; LF, lipofilling.

DM (1.6\%), whereas in the group of Controls there were 5 LRR (4\%) and 7 DM (5.6\%), with the amount of TR counting up to $5(4 \%)$ and $12(9.6 \%)$, respectively. There are no statistically significant differences between Cases and Controls in LRR, DM and TR in the univariate analysis (log-rank $\mathrm{P}$ value $=0.183,0.200$ and 0.065 respectively) (Figures 1,2).

Table 2 shows the subgroup analysis in relation to the presence of LRR, DM and TR and the following characteristics: histological and biomolecular tumor subtype and type of oncologic surgery. There are not statistically significant differences in any of the analysis.

Table 3 shows the Lipofilling characteristics in our patients, including number of lipofilling sessions, total of cc of fat grafting injected and time from the oncologic surgery to the lipofilling. No statistically significant differences were found.

We analyzed the characteristics of the lipofilling according to the type of oncologic surgery that was performed in two separate groups: mastectomy and breast conserving surgery. We found that there are not statistically significant differences in the number of sessions of fat grafting required amongst the two groups (2.07 and 1.745 respectively; $\mathrm{P}=0.067)$; neither in the average of fat injected (158.1 and 156.7 respectively; $\mathrm{P}=0.948$ ). On the other hand, there are statistically significant differences $(\mathrm{P}<0.05)$ in the timing that the lipofilling was performed since the oncologic surgery: a median of 46 months was observed in the group of breast conserving surgery (95\% CI: 37.3-54.7) and 28 months in the group of mastectomy (95\% CI: $22.7-$ 33.3). This might be because the defect resulting from the breast conserving surgery gets worse over time due to the retraction of tissues because of Radiotherapy, whether the mastectomy defect is more evident earlier.

A multivariate analysis with a Cox regression model was performed to analyze how different characteristics affect to the total number of metastasis (Table 4). There is no increased risk in the lipofilling group, with a hazard ratio (HR) of 0.30 (95\% CI: $0.09-1.01)$. The only factor that is independently associated with an increased risk of TR is the size of the breast tumor (pT). Tumors less than $5 \mathrm{~cm}$ present with less risk of TR compared to those bigger than $5 \mathrm{~cm}(\mathrm{HR}=0.017,95 \%$ CI: 0.04-0.71). The relative risk (RR) was analyzed for this variable in the lipofilling group, and the result was not statistically significant $(1.035,95 \%$ CI: 0.921-1.135).

\section{Discussion}

Lipofilling is an increasingly popular technique with multiple applications in breast reconstruction, different reconstructive fields and aesthetic surgery $(4,26)$. Because of that, is necessary to establish the oncological safety of this technique, especially in patients with history of cancer.

At least, 41 non-overlapping studies have previously reported LRR and DM rates after lipofilling, but the oncologic safety of lipofilling still remains unknown, despite the fact that the great majority of evidence suggests similar outcomes between lipofilling and control patients (27). In spite of that, the great capacity of fat tissue in secreting hormones, growth factors and cytokines together with the experimental studies in vitro and in animals showing that adipocytes are able to produce growth factors involved in tumorigenesis, new studies are necessary to support the oncological safety of fat grafting $(8,28)$.

With this aim, we have designed a study that included all patients treated with lipofilling in our center between 2011 and 2019, matching them with a control group with similar characteristics.

If we consider for a moment that lipofilling may be a risk factor for relapse development, it would be reasonable to assume that the more lipofilling sessions or the larger the fat graft volume used for breast reconstruction should result in an increased risk of recurrence. In our study there are not statistically significant differences when analyzing the 
Table 5 Comparison amongst different articles about locoregional recurrence in patients who received fat grafting treatments

\begin{tabular}{llccc}
\hline & LRR $^{\dagger}$ & LRR & Follow up from the first fat grafting procedure (months) & N \\
\hline Petit et al. (32) & $2.5 \%$ & $1.60 \% /$ year & 26 & 513 \\
Silva-Vergara et al. (14) & $3.4 \%$ & $1.00 \% /$ year & 30 & 205 \\
Gale et al. (16) & $1.9 \%$ & $0.71 \% /$ year & 51 & 211 \\
Sorrentino et al. (30) & $6.4 \%$ & $1.51 \% /$ year & 28 & 660 \\
Kronowitz et al. (17) & $1.4 \%$ & $0.58 \% /$ year & 47 & 125 \\
Our study & $2.4 \%$ & $0.61 \% /$ year & & \\
\hline
\end{tabular}

${ }^{\dagger}$ Locoregional recurrences.

number of lipofilling sessions and the volume of fat graft injected (Table 3).

Petit et al. (29) and Silva-Vergara et al. (14) presented 2 studies showing an increase of LRR when the lipofilling is performed within the first 3 years after the oncologic surgery. However, Sorrentino et al. (30) divides the interval in the first year after the oncologic surgery and within the second and third years after the oncologic surgery, with no statistically significant differences found in the total of LRR. Our study does not show statistically significant differences in the rate of LRR in the patients receiving the lipofilling within the first 3 years after the oncologic surgery and the ones after that $(\log$-rank $\mathrm{P}$ value $=0.317)$.

Petit et al. (29) described that the use of lipofilling in patients with intraepithelial neoplasia increase the risk of LRR in breast conservative surgery. We have also investigated this risk, finding no statistically significant differences (Log-rank P value $=0.514)$. We have also analyzed the risk of LRR in patients with invasive carcinoma and breast conserving surgery and the result is not statistically significant $(\log$ rank $P$ value $=0.157)$ regardless of using or not lipofilling.

Recently, a meta-analysis that included 4,292 patients demonstrated a non-significant incidence rate difference in LRR of $0.15 \%$ per year between autologous fat grafting and control patients, providing robust evidence of autologous fat grafting safety after breast cancer (27). However, the median follow-up since the timing of the lipofilling was only 32.4 months for the included studies. Knowing the long-lasting natural history of breast cancer, a short followup period may underestimate the incidence of potential LRR. In our study the median follow-up time since the first session of lipofilling was 47.2 months (6-113 months). In our study, there are not statistically significant differences in the presence of LRR between Cases and Controls (Figure 1).
Kronowitz et al. (17) describe a hypothetical potential role of hormonal therapy by enhancing a tumorigenic microenvironment between adipose-derived mesenchymal stem cells and breast cancer cells that may explain their results. They found almost 3 times more risk of LRR with lipofilling in patients who received hormonal therapy $(\mathrm{P}=0.038)$. In the case that this was correct, it would be necessary to select the patients with lipofilling since adjuvant hormone therapy in early staged breast cancer increases the disease-free survival and overall survival rates (31). There are not statistically significant differences in our study but given the importance of hormone adjuvant therapy in breast cancer, further studies would be necessary in this regard.

Table 5 shows the incidence of LRR (\%LRR), incidencedensity rates (LRR/year), follow-up time and number of patients included in our study sample compared to other published studies with similar characteristics $(14,16,17,30,32)$. Our study shows a LRR rate of $2.4 \%$ and an incidence-density rate of $0.61 \% / y e a r$. This incidencedensity rate is the second lowest one from the published studies in Table 5. The incidence-density rate is among the one published by Krastev et al. (27) $0.73 \% /$ year (95\% CI: 0.56-0.94) in his meta-analysis in which 4,292 patients with lipofilling were included with a median follow-up of 32 months.

A strong point of our study is that is one of the studies with longest time of follow-up after lipofilling (mean $=47.2$ months ) and one with the highest number of matching variables with the Control group (eight) which gives a sample with great homogeneity with the Control group.

Cohen et al. (33) described seven criteria that should be present in a study for considering lipofilling as a safe technique in the setting of breast conserving surgery: (I) 
a description of the interval between cancer resection and lipofilling, (II) a minimum follow-up period of 6 years after primary cancer resection, (III) a minimum follow-up period of 3 years after lipofilling, (IV) an analysis of breast cancer sub-groups specifically focusing on ER/PR/Her2, (V) a defined cohort comparison group, (VI) controls matched for receptor status, (VII) adequate powering. None of the 19 studies which are analyzed in this article meet all the criteria. Only one study satisfies six out of seven criteria; and other study follows five of seven criteria. The rest of the articles fulfil four or less criteria. Our study meets five of seven of these criteria ( $\mathrm{I}$ to $\mathrm{V}$ ). It also partially satisfies the point VI (one of our matching variables in the control group is Her2 status). This is another strong point of our study.

Our study has two limitations: it is a retrospective study and it has limited number of patients. Due to its retrospective design, it lacks a defined time interval for the fat injection after the initial surgery. The fact that different patients get injected at variable times after the oncological surgery and in different intervals between the lipofilling sessions might act as a cofounder variable.

A prospective randomized trial with a larger number of participants is needed to achieve more definitive results.

\section{Conclusions}

Autologous fat grafting remains an attractive procedure for optimizing aesthetic outcomes in the process of breast reconstruction. Although its definitive impact on LRR remains unclear, our study shows that this procedure does not increase the LRR. These findings should encourage long prospective trials to provide surgeons with accurate information regarding the role of lipofilling on breast neoplasm.

\section{Acknowledgments}

The statistical analysis was supervised by Jesus Maria Gonzalez, Statistician from the Research Department of the University Hospital Dr. Negrín.

Funding: None.

\section{Footnote}

Reporting Checklist: The authors have completed the STROBE reporting checklist. Available at http://dx.doi. org/10.21037/gs-20-775
Data Sharing Statement: Available at http://dx.doi. org/10.21037/gs-20-775

Peer Review File: Available at http://dx.doi.org/10.21037/gs20-775

Conflicts of Interest: All authors have completed the ICMJE uniform disclosure form (available at http://dx.doi. org/10.21037/gs-20-775). The authors have no conflicts of interest to declare.

Etbical Statement: The authors are accountable for all aspects of the work in ensuring that questions related to the accuracy or integrity of any part of the work are appropriately investigated and resolved. The study was conducted in accordance with the Declaration of Helsinki (as revised in 2013). The study was approved by institutional ethics committee of University Hospital Dr Negrin (No. 2020-352-1) and individual consent for this retrospective analysis was waived.

Open Access Statement: This is an Open Access article distributed in accordance with the Creative Commons Attribution-NonCommercial-NoDerivs 4.0 International License (CC BY-NC-ND 4.0), which permits the noncommercial replication and distribution of the article with the strict proviso that no changes or edits are made and the original work is properly cited (including links to both the formal publication through the relevant DOI and the license). See: https://creativecommons.org/licenses/by-ncnd $/ 4.0 /$.

\section{References}

1. Katzel EB, Bucky LP. Fat Grafting to the Breast: Clinical Applications and Outcomes for Reconstructive Surgery. Plast Reconstr Surg 2017;140:69S-76S.

2. Bayram Y, Sezgic M, Karakol P, et al. The use of autologous fat grafts in breast surgery: A literature review. Arch Plast Surg 2019;46:498-510.

3. Spear SL, Wilson HB, Lockwood MD. Fat injection to correct contour deformities in the reconstructed breast. Plast Reconstr Surg 2005;116:1300-5.

4. Khouri RK Jr, Khouri RK. Current Clinical Applications of Fat Grafting. Plast Reconstr Surg 2017;140:466e-486e.

5. Simonacci F, Bertozzi N, Grieco MP, et al. Procedure, applications, and outcomes of autologous fat grafting. 
Ann Med Surg (Lond) 2017;20:49-60.

6. Gutowski KA, ASPS Fat Graft Task Force. Current applications and safety of autologous fat grafts: a report of the ASPS fat graft task force. Plast Reconstr Surg 2009;124:272-80.

7. Shih L, Abu-Ghname A, Davis MJ, et al. Applications of Fat Grafting in Pediatric Patients. Semin Plast Surg 2020;34:53-8.

8. Zhang Y, Daquinag A, Traktuev DO, et al. White adipose tissue cells are recruited by experimental tumors and promote cancer progression in mouse models. Cancer Res 2009;69:5259-66.

9. Motrescu ER, Rio MC. Cancer cells, adipocytes and matrix metalloproteinase 11: a vicious tumor progression. Biol Chem 2008;389:1037-41.

10. Pearl RA, Leedman SJ, Pacifico MD. The safety of autologous fat transfer in breast cancer: lessons from stem cell biology. J Plast Reconstr Aesthet Surg 2012;65:283-8.

11. Massa M, Gasparini S, Baldelli I, et al. Interaction Between Breast Cancer Cells and Adipose Tissue Cells Derived from Fat Grafting. Aesthet Surg J 2016;36:358-63.

12. Lohsiriwat V, Curigliano G, Rietjens $M$, et al. Autologous fat transplantation in patients with breast cancer: "silencing" or "fueling" cancer recurrence? Breast 2011;20:351-7.

13. Silva MMA, Kokai LE, Donnenberg VS, et al. Oncologic Safety of Fat Grafting for Autologous Breast Reconstruction in an Animal Model of Residual Breast Cancer. Plast Reconstr Surg 2019;143:103-12.

14. Silva-Vergara C, Fontdevilla J, Weshahy O, et al. Breast Cancer Recurrence Is not Increased With Lipofilling Reconstruction: A Case-Controlled Study. Ann Plast Surg 2017;79:243-8.

15. Petit JY, Botteri E, Lohsiriwat V, et al. Locoregional recurrence risk after lipofilling in breast cancer patients. Ann Oncol 2012;23:582-8.

16. Gale KL, Rakha EA, Ball G, et al. A case-controlled study of the oncologic safety of fat grafting. Plast Reconstr Surg 2015;135:1263-75.

17. Kronowitz SJ, Mandujano CC, Liu J, et al. Lipofilling of the breast does not increase the risk of recurrence of breast cancer: a matched controlled study. Plast Reconstr Surg 2016;137:385-93.

18. Fat Transfer/Fat Graft and Fat Injection ASPS Guiding Principles. Available online: www.plasticsurgery.org.

19. Haute Autorité de Santé. Evaluation de la sécurité et des conditions de réalisation de l'autogreffe de tissu adipeux dans la chirurgie reconstructrice, réparatrice et esthétique du sein. Saint-Denis La Plaine: HAS; 2015.

20. Fisher B, Anderson S, Bryant J, et al. Twenty-year follow-up of a randomized trial comparing total mastectomy, lumpectomy, and lumpectomy plus irradiation for the treatment of invasive breast cancer. $\mathrm{N}$ Engl J Med 2002;347:1233-41.

21. Coleman SR. Structural fat grafts: the ideal filler? Clin Plast Surg 2001;28:111-9.

22. Coleman SR. Long-term survival of fat transplants: controlled demonstrations. Aesthetic Plast Surg 1995;19:421-5.

23. Jones ME, Schoemaker MJ, Wright LB, et al. Smoking and risk of breast cancer in the Generations Study cohort. Breast Cancer Res 2017;19:118.

24. Tsilidis KK, Kasimis JC, Lopez DS, et al. Type 2 diabetes and cancer: umbrella review of meta-analyses of observational studies. BMJ 2015;350:g7607.

25. Sarfati I, Ihrai T, Kaufman G, et al. Adipose-tissue grafting to the post-mastectomy irradiated chest wall: Preparing the ground for implant reconstruction. J Plast Reconstr Aesthet Surg 2011;64:1161-6.

26. Delay E, Garson S, Tousson G, et al. Fat injection to the breast: technique, results, and indications based on 880 procedures over 10 years. Aesthet Surg J 2009;29:360-76.

27. Krastev TK, Schop SJ, Hommes J, et al. Meta-analysis of the oncological safety of autologous fat transfer after breast cancer. Br J Surg 2018;105:1082-97.

28. Kilroy GE, Foster SJ, Wu X, et al. Cytokine profile of human adipose-derived stem cells: expression of angiogenic, hematopoietic, and pro-inflammatory factors. J Cell Physiol 2007;212:702-9.

29. Petit JY, Rietjens M, Botteri E, et al. Evaluation of fat grafting safety in patients with intraepithelial neoplasia: a matched-cohort study. Ann Oncol 2013;24:1479-84.

30. Sorrentino L, Regolo L, Scoccia E, et al. Autologous Fat Transfer After Breast Cancer Surgery: An ExactMatching Study on the Long-Term Oncological Safety. Eur J Surg Oncol 2019;45:1827-34.

31. Early Breast Cancer Trialists' Collaborative Group (EBCTCG), Davies C, Godwin J, et al. Relevance of breast cancer hormone receptors and other factors to the efficacy of adjuvant tamoxifen: patient-level metaanalysis of randomised trials. Lancet 2011;378:771-84.

32. Petit JY, Lohsiriwat V, Clough KB, et al. The oncologic outcome and immediate surgical complications of 
lipofilling in breast cancer patients: a multicenter study - Milan-Paris-Lyon experience of 646 lipofilling procedures. Plast Reconstr Surg 2011;128:341-6.

33. Cohen S, Sekigami Y, Schwartz T, et al. Lipofilling after

Cite this article as: Casarrubios JM, Francés $M$, Fuertes V, Singer M, Navarro C, García-Duque O, Fernández-Palacios $\mathrm{J}$. Oncological outcomes of lipofilling in breast reconstruction: a matched cohort study with 250 patients. Gland Surg 2021;10(3):914-923. doi: 10.21037/gs-20-775 breast conserving surgery: a comprehensive literature review investigating its oncologic safety. Gland Surg 2019;8:569-580. 